\title{
Predator chemical cues increase growth and alter development in nauplii of a marine copepod
}

\author{
Oda Bjærke*, Tom Andersen, Josefin Titelman \\ Department of Biosciences, University of Oslo, PO Box 1066, Blindern, 0316 Oslo, Norway
}

\begin{abstract}
Copepods are a fundamental trophic link in the marine food web. While much attention has been devoted to the role of temperature and food for copepod development and growth, little is known about how marine copepods adjust their life history according to the prevailing predation risk. This is striking, considering the potential advantage of risk-sensitive life history, and the many reports of freshwater zooplankton showing strong effects of risk cues on growth and development. Here, we measured growth and development in nauplii of the marine copepod Temora longicornis. We incubated newly hatched nauplii individually with or without a predator chemical cue. Individuals were followed and measured repeatedly over time, generating highresolution data. We estimated treatment-specific stage transition probabilities from daily molting frequencies. The nauplii showed an increased growth rate when exposed to fish kairomones. However, the corresponding response in development differed between stages, with the later naupliar stages generally displaying a higher molting probability and higher body mass (ash-free dry weight) per stage. These results suggest that development and growth in marine copepods is flexible and sensitive to predation risk. Our findings also indicate that investment in growth might be beneficial in copepods despite higher visibility.
\end{abstract}

KEY WORDS: Zooplankton $\cdot$ Risk $\cdot$ Life history $\cdot$ Molting $\cdot$ Plasticity

\section{INTRODUCTION}

All organisms release compounds, which in the sea make up a complex environment of chemical cues. Some of these cues carry valuable information for conspecifics and other interacting species. Detection and interpretation of chemical information can profoundly shape interactions and food web dynamics in marine systems (Hay \& Kubanek 2002, Weissburg et al. 2002). Chemical cues of predation risk can be alarm signals emitted by stressed or disturbed conspecifics, or it can be odor from the predator organism, either as dietary cues from digested prey, or as kairomones, which are exudates from the predator animal itself (Ferrari et al. 2010). By definition, kairomones benefit the receiver, but not the emitter.

Copepods are essential as a link in the marine food web, transferring energy from protists to higher trophic levels (Turner 2004). As a common prey for

${ }^{*}$ Corresponding author: oda.bjarke@ibv.uio.no large fish stocks, copepods have evolved several predator-avoidance strategies. However, copepods experience predation risk at different levels and time scales. The short-term acute risk related to pursuit or attack is mediated by hydrodynamic cues, and triggers escape jumps. These responses have been thoroughly studied (Fields \& Yen 1997, Titelman 2001, Buskey et al. 2002). The intensity of the general risk regime, however, can fluctuate on longer daily or seasonal scales depending on predator abundances. The risk regime might be reflected in the concentration of predator kairomones. Copepods are highly sensitive to chemical information about conspecifics and food, and are suggested to also detect risk via kairomones (Heuschele \& Selander 2014).

Variation in risk regime can potentially affect both behavior and growth patterns, as life history traits are generally sensitive to predation (Stearns 1992).

(C) The authors 2014. Open Access under Creative Commons by Attribution Licence. Use, distribution and reproduction are unrestricted. Authors and original publication must be credited. 
Risk might select for a higher developmental rate and reduced growth resulting in smaller size at stage and earlier maturation. This can be expected when there is no advantage of attaining large size (Stibor 1992, Nylin \& Gotthard 1998). Conversely, when larger size entails protection against the predator, allocation of resources in growth rather than early reproduction is rewarding, as the prey would grow into a size refuge earlier (Chase 1999, Urban \& Threat 2007). For copepods, risk is size dependent. Detectability scales with size, and larger individuals therefore have higher encounter rates with predators, and are thus more vulnerable (Aksnes \& Utne 1997). On the other hand, increased size can also give an advantage in terms of higher motility and more efficient escape responses (Kiørboe \& Visser 1999, Andersen Borg et al. 2012). Behavioral defense strategies also develop during the ontogeny.

Here, we define 'growth' as the accumulated increase in body mass, and 'development' as the change towards an increasingly more organized state; in copepods this is manifested in the molting to successive developmental stages. Growth and development are partially uncoupled processes in copepods (Forster et al. 2011). This creates a flexibility that allows for optimization according to the prevailing risk regime, which would be advantageous (Abrams et al. 1996). However, the optimal strategy depends on the relative strength of size-dependent vulnerability and protection. Risk might also vary between the developmental stages (Neill 1992). Ontogenetic changes in susceptibility to predation could be reflected in stage-specific responses, for example, as accelerated development through the most vulnerable stages (Peterson 2001). Decades of laboratory and field studies show that copepod growth patterns vary considerably in response to food and temperature regimes. While the impact of food conditions on copepod growth (Breteler et al. 1982, 1990, Koski et al. 1998) and the temperature dependence in development (Huntley \& Lopez 1992, Cook et al. 2007, Forster et al. 2011) are well documented, the role of predation risk is unclear.

The literature on chemically mediated predatorprey interactions in plankton is increasing rapidly. Several examples from phytoplankton show strong grazer-induced responses in morphology and growth (Hessen \& van Donk 1993, Selander et al. 2011, Bergkvist et al. 2012). The flagellate Phaeocystis even responds specifically to functionally different grazers, and thereby reduces grazing losses (Long et al. 2007). In marine copepods, kairomones can influence reproduction (Lasley-Rasher \& Yen 2012,
Wasserman \& Froneman 2013), and behavior (reviewed in Heuschele \& Selander 2014). However, most studies of zooplankton and fish kairomones originate from freshwater systems, in particular those concerning life history responses (Verity \& Smetacek 1996, Lass \& Spaak 2003, Gutierrez et al. 2011). Cladocerans are the traditional model organisms and typically alter their life history when exposed to predator chemical cues (e.g. Stibor 1992, Macháček 1995). However, food webs and hence the chemical environment are more complex in the ocean than in lakes. Also, the life cycle, reproductive biology and behavior differ tremendously between sexually reproducing copepods and parthenogenetic cladocerans. Whether similar responses as those found in fresh water apply to marine copepods is uncertain.

The only study showing effects of predation risk on development in a freshwater copepod focused on the copepodites stages (C1 to C6) (Gutierrez et al. 2010). Considering that the naupliar stages (N1 to N6) numerically dominate copepod communities, any impact on growth and development in nauplii is equally important as the effects on later stages. Stage-specific responses to chemical predator cues have to our knowledge never been investigated in marine copepod nauplii. Here, we tested responses to predator chemical cues on growth and development in the coastal marine copepod Temora longicornis during the naupliar stages.

\section{MATERIALS AND METHODS}

Zooplankton were collected with a WP-2 net (200 $\mu \mathrm{m}$ mesh), manually towed from 50 to $0 \mathrm{~m}$ in the Oslo Fjord in May 2011. We immediately sorted the live samples in the laboratory, and started a continuous culture with adult Temora longicornis. The stock cultures were kept in 501 tanks with aerated filtered sea water, and fed ad libitum with a mixture of live Rhodomonas baltica and instant algae Thalassiosira weissflogi and Isochrysis galbana (Reed Mariculture $\left(\right.$ ). Cultures were maintained at $15^{\circ} \mathrm{C}$ with a 12:12 h light-dark cycle.

We performed an incubation experiment with 2 treatments, risk and control, to monitor naupliar growth and development patterns. Measuring individual nauplii over time gave high-resolution size and stage data. The risk treatment consisted of kairomones from the three-spined stickleback Gasterosteus aculeatus. Sticklebacks are planktivorous, feeding efficiently on coexisting $T$. longicornis (Viitasalo et al. 1998). The three-spined stickleback is 
generally a relevant model organism, its foraging ecology is well-described, and its kairomones have been studied (von Elert \& Pohnert 2000). We obtained kairomones by incubating sticklebacks in filtered seawater at a concentration of 2 individuals $\mathrm{l}^{-1}$ for $5 \mathrm{~h}$ in a glass aquarium (12 sticklebacks in $6 \mathrm{l}$ water). This fish concentration exceeded average natural fish densities. However, a strong cue was chosen to compensate for rapid degradation of the kairomones in non-sterile conditions (Loose et al. 1993). The sticklebacks were fed with chironomid larvae prior to the incubations. The water was constantly aerated to maintain $\mathrm{O}_{2}$ saturation. After removing the fish, the water was filtered through a $30 \mu \mathrm{m}$ sieve. Water for the control group was prepared in an identical manner, but without fish. Control and treatment water was prepared daily during the experiment. Before use, we added $R$. baltica ad libitum (600 $\mathrm{g} \mathrm{C} \mathrm{C}^{-1}$ ) (Koski 2006) to the incubation water.

The experiment was designed to monitor the growth of 40 individuals that survived during the experiment $(14 \mathrm{~d})$. We collected $T$. longicornis eggs from the stock culture and left them to hatch for $8 \mathrm{~h}$. This procedure was repeated on different start dates in a 5 wk period. The newly hatched nauplii at stage N1 were randomly assigned to risk treatment $(\mathrm{n}=20)$ or control treatment $(n=20)$, and were incubated individually in $15 \mathrm{ml}$ wells (6 well plate, Thermo Scientific Nunc ${ }^{\mathrm{TM}}$ ) kept at $16^{\circ} \mathrm{C}$ under a natural light regime. Every day, each nauplius was transferred to a new well with freshly prepared incubation water.

From Day 2 to 14, we photographed each nauplius daily using a Canon EOS 7D (17.9 mp) equipped with a macro lens (Canon MP-e65mm f/2.8, 5× magnification) allowing for a resolution of $0.85 \mu \mathrm{m} \mathrm{pixel}{ }^{-1}$. The camera was mounted facing upwards, viewing the nauplii in a droplet on a microscope slide from below. A reference picture for each day was taken to calibrate the pixel scale for length measurements. For each individual, we recorded the start date and time, as well as the time for each subsequent picture. From the pictures, we quantified the width and total length (TL) excluding caudal spines for nauplii, using the image processing program Image J 1.44 (Rasband 2011). For the copepodite stages, we measured prosome length instead of TL. We also determined the developmental stage based on Ogilvie (1953). The TL $(\mu \mathrm{m})$ was converted to body mass in ash-free dry weight (AFDW, $\mu \mathrm{g}$ ) using the formula derived from Breteler et al. (1982):

$$
\operatorname{AFDW}(\mu g)=10^{2.167 \log _{10}(\mathrm{TL})-5.534}
$$

For the observations of stage $\mathrm{C} 1$, the conversion formula for copepodites was used:

$$
\operatorname{AFDW}(\mu \mathrm{g})=10^{3.064 \log _{10}(\mathrm{TL})-7.696}
$$

\section{Statistical analyses}

The data were analyzed using the statistical computing system R (R Development Core Team 2010). We tested the difference in growth rate with a linear mixed effect (LME) model using the nlme package (Pinheiro et al. 2013). The natural logarithm of AFDW was used as a response variable in the analysis to meet the assumptions of homogenous model residuals. As the measurements started the day after hatching, we had only a few observations of stage N1. These were considered outliers and not included in the LME analysis. The experimental design required a model structure that accounted for the repeated measurements on the same individuals over time. Thus, we included time $(t)$ grouped by individual $(j)$ in the model as random effects. The fixed effects were treatment $(T)$, time, and the interaction. Based on Aikaike's information criterion values, individual start date was excluded as a covariate. Finally, the following LME model with random intercept and slope was fitted:

$$
\begin{aligned}
& \log \operatorname{AFDW}_{i j}= \\
& \left(\beta_{0}+\mathrm{b}_{0, j}\right)+\beta_{1} T_{j}+\left(\beta_{2}+\mathrm{b}_{2, j}\right) t_{i}+\beta_{3} t_{i} T_{j}+\varepsilon_{i, j}
\end{aligned}
$$

where $\beta_{0-3}$ are the estimates for fixed effects, and $b_{0}$ and $b_{2}$ are the random intercept and slope, $i$ is observation index, and $\varepsilon$ is the unexplained variance. Differences in AFDW at each stage between treatments were tested with 2-sided Wilcoxon rank sum tests using mean individual AFDW at stage. We calculated the individual aspect ratio (length:width), and tested for differences in aspect ratio between treatments for each stage with $t$-tests.

Molting probabilities from one developmental stage to the next were represented by transition probability matrices (Caswell 1989). In a given observation interval, a nauplius can either remain in the same stage or molt to the next:

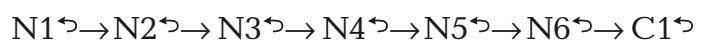

We had stage observations $(S)$ of each individual $j$ every day $d$, in treatment $T$. These stage observations can be cross-tabulated into a transition frequency table, as shown here for the total observations during the entire experiment: 


$$
\mathbf{M}=\begin{array}{cccccccc} 
& \text { N1 } & \text { N2 } & \text { N3 } & \text { N4 } & \text { N5 } & \text { N6 } & \text { C1 } \\
\text { N1 } & 7 & 0 & 0 & 0 & 0 & 0 & 0 \\
\text { N2 } & 40 & 83 & 0 & 0 & 0 & 0 & 0 \\
\text { N3 } & 0 & 40 & 90 & 0 & 0 & 0 & 0 \\
\text { N4 } & 0 & 0 & 40 & 97 & 0 & 0 & 0 \\
\text { N5 } & 0 & 0 & 0 & 37 & 52 & 0 & 0 \\
\text { N6 } & 0 & 0 & 0 & 0 & 15 & 14 & 0 \\
\text { C1 } & 0 & 0 & 0 & 0 & 0 & 2 & 3
\end{array}
$$

The diagonal elements in $\mathbf{M}$ are the number of individuals that remain in the same stage during one day, and the sub-diagonal elements are the number of transitions to the next stage during one day. The column sums of $\mathbf{M}$ are given by:

$$
\mathbf{m} .=\sum_{i} m_{i j}=\left[\begin{array}{c}
47 \\
123 \\
130 \\
134 \\
67 \\
16 \\
3
\end{array}\right]
$$

The probability matrix $\mathbf{P}$ is the normalized version of $\mathbf{M}$, with the transition probabilities in the subdiagonal elements (shaded):

$\mathbf{P}=\left[\frac{m_{i j}}{m_{\cdot j}}\right]=\left[\begin{array}{ccccccc}0.15 & 0 & 0 & 0 & 0 & 0 & 0 \\ 0.85 & 0.67 & 0 & 0 & 0 & 0 & 0 \\ 0 & 0.33 & 0.69 & 0 & 0 & 0 & 0 \\ 0 & 0 & 0.31 & 0.72 & 0 & 0 & 0 \\ 0 & 0 & 0 & 0.28 & 0.78 & 0 & 0 \\ 0 & 0 & 0 & 0 & 0.22 & 0.88 & 0 \\ 0 & 0 & 0 & 0 & 0 & 0.12 & 1\end{array}\right]$

To investigate the differences in molting rate between the treatment groups we calculated probability matrices separately for the risk and control treatments. First, we performed a bootstrap procedure of stage observations for each treatment. Having stage observations $S_{d, j, T}$, for each day, individual, and treatment, we resampled unique individuals within treatments with replacement, and repeated this procedure 1000 times. After cross-tabulation and normalization as described above, we had 1000 probability matrices for each treatment. From this, we obtained bootstrap distributions for all transition probabilities within each treatment. Bootstrap distributions of the log odds ratios between treatmentspecific stage transition probabilities ( $p_{\text {Risk }}$ and $p_{\text {Control }}$ ) were calculated for each bootstrap sample as:

$$
\log \text { odds }- \text { ratio }=\log \frac{p_{\text {Risk }} /\left(1-p_{\text {Risk }}\right)}{p_{\text {Control }} /\left(1-p_{\text {Control }}\right)}
$$

The nauplii in the control treatment did not reach stage $\mathrm{C} 1$ within the experimental period, such that the log odds ratio could not be calculated for the last molting (N6 to $\mathrm{C} 1$ ).

Finally, we used transition probabilities to estimate stage frequencies over time (Fig. 1). The stage frequencies for a population at day $d$ are given by the vector $\mathbf{n}(d)$ with rows representing the 7 stages from $\mathrm{N} 1$ to $\mathrm{C} 1$. The stage frequencies for populations over time can be estimated by projection of the probability matrix onto the initial stage frequency (Kammenga et al. 2001). The measurements started on Day 1. However, we assumed that all individuals were in stage N1 on Day 0, with the initial stage frequency given by:

$$
\mathbf{n}(0)=\left[\begin{array}{l}
1 \\
0 \\
0 \\
0 \\
0 \\
0 \\
0
\end{array}\right]
$$

Multiplication of $\mathbf{n}(0)$ by $\mathbf{P}$ gives the resultant vector $\mathbf{n}(1)$ with the stage frequencies at Day 1 . We projected the stage frequency through $14 \mathrm{~d}$ separately for risk and control treatments with the model:

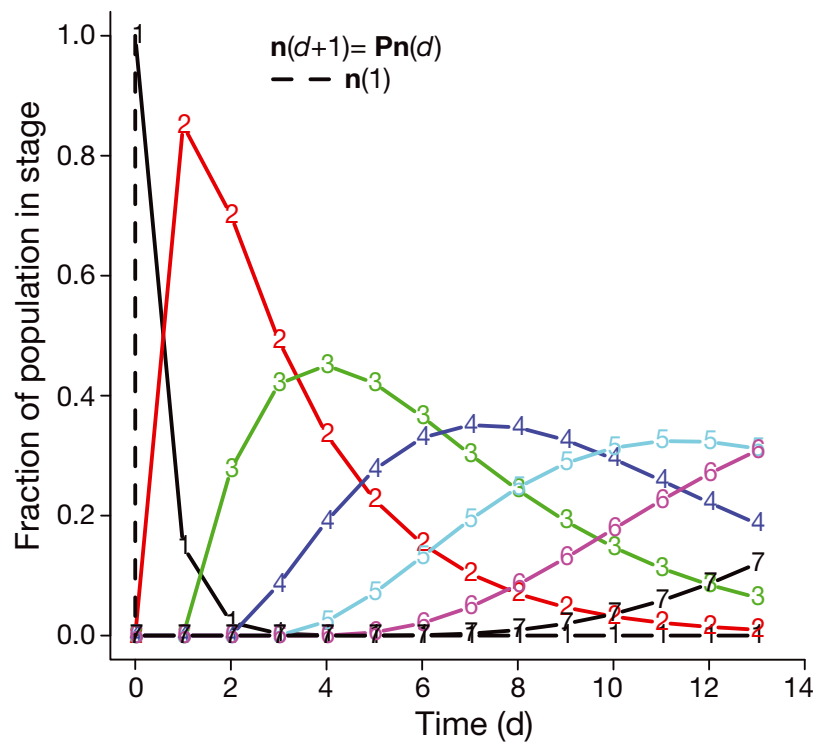

Fig. 1. Simulated stage frequency distribution for a cohort over $14 \mathrm{~d}$ based on all the nauplii in the experiment together. The numbers on the lines are the stages, where 1 is $\mathrm{N} 1$ and 7 is $\mathrm{C} 1$. The stage frequencies were calculated by projection of a transition probability matrix (Eq. 10) 


$$
\mathbf{n}(d+1)=\mathbf{P} \mathbf{n}(d)
$$

Finally, we estimated the individual AFDW in a simulated cohort with each treatment over time by multiplication of the treatment- and stage-specific AFDW by the stage frequencies for each day.

\section{RESULTS}

Growth rate increased for nauplii exposed to the predator cue (Fig. 2), as shown by a significant interaction of risk treatment and time on AFDW (Table 1). While the nauplii in the control treatment grew at $7.37 \% \mathrm{~d}^{-1}( \pm 0.0063 \mathrm{SE})$, those that were exposed to risk cues increased their AFDW by $10.88 \% \mathrm{~d}^{-1}$ $( \pm 0.0063 \mathrm{SE})(\mathrm{LME}, \mathrm{p}=0.0001$, Table 1$)$. The AFDW at each stage suggested a shift in response to risk between stages N3 and N4 with higher AFDW per stage with risk treatment in the late naupliar stages (Fig. 3). However, analyses of AFDW for each stage separately revealed a significant effect of risk only at stage N5 (2-sided Wilcoxon rank sum tests, N2: n = $20, m=20, p=0.87 ; N 3: n=20, m=20, p=0.99$ N4:

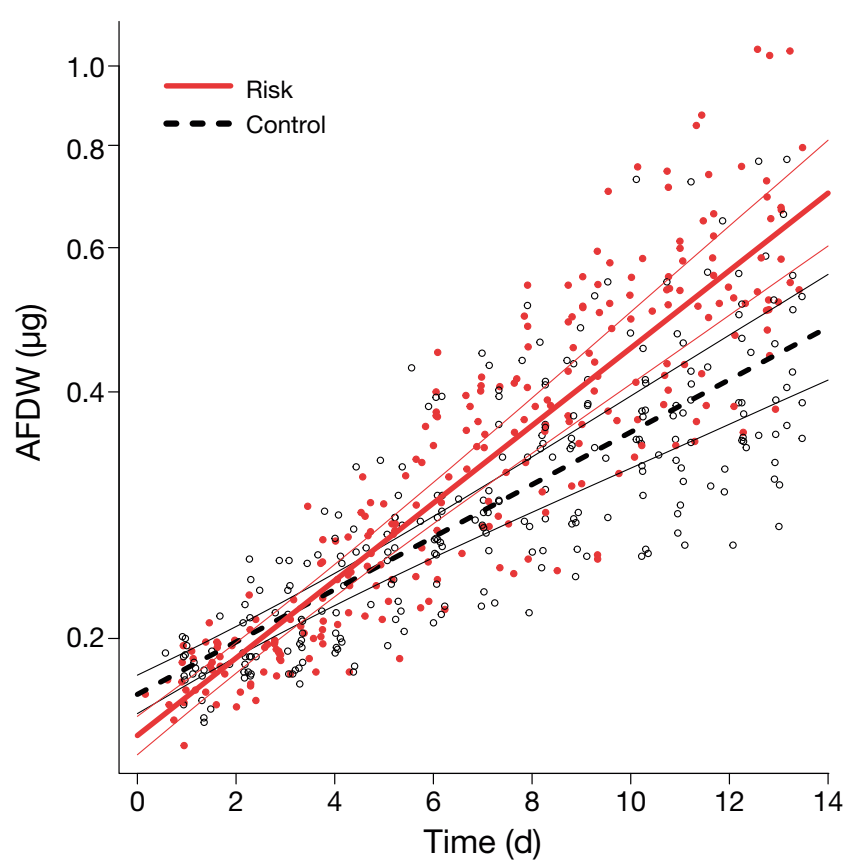

Fig. 2. Body mass, in $\mu g$ ash-free dry weight (AFDW), as a function of time for Temora longicornis nauplii. The points are observed values of total length converted to AFDW. The thick lines represent predicted growth rates for nauplii with risk $\left(10.88 \% \mathrm{~d}^{-1} \pm 0.0063 \mathrm{SE}\right.$, intercept $\left.=0.15\right)$ and control treatment $\left(7.37 \% \mathrm{~d}^{-1} \pm 0.0063 \mathrm{SE}\right.$, intercept $\left.=0.17\right)$. The thin lines around the growth rates represent 95\% confidence intervals for the estimated growth rates (linear mixed effect model, $\mathrm{n}=40, \mathrm{p}=0.0001$ ). Note the log scale on the $y$-axis
Table 1. Model output of fixed effects from linear mixed effect model of ash-free dry weight (AFDW, $\mu \mathrm{g}$ ), with treatment, time, and the interaction. Time grouped by individual was included as a random effect (Eq. 3)

\begin{tabular}{|lccrrrr|}
\hline & Log AFDW & SE & df & $t$ & $\mathrm{p}$ \\
\hline Intercept & -1.77 & 0.027 & 470 & -65.38 & $<0.0001$ \\
Treatment & -0.12 & 0.038 & 38 & -3.03 & 0.0044 \\
Time & 0.074 & 0.0063 & 470 & 11.65 & $<0.0001$ \\
Time $\times$ Treatment & 0.035 & 0.0089 & 470 & 3.93 & 0.0001 \\
\hline
\end{tabular}

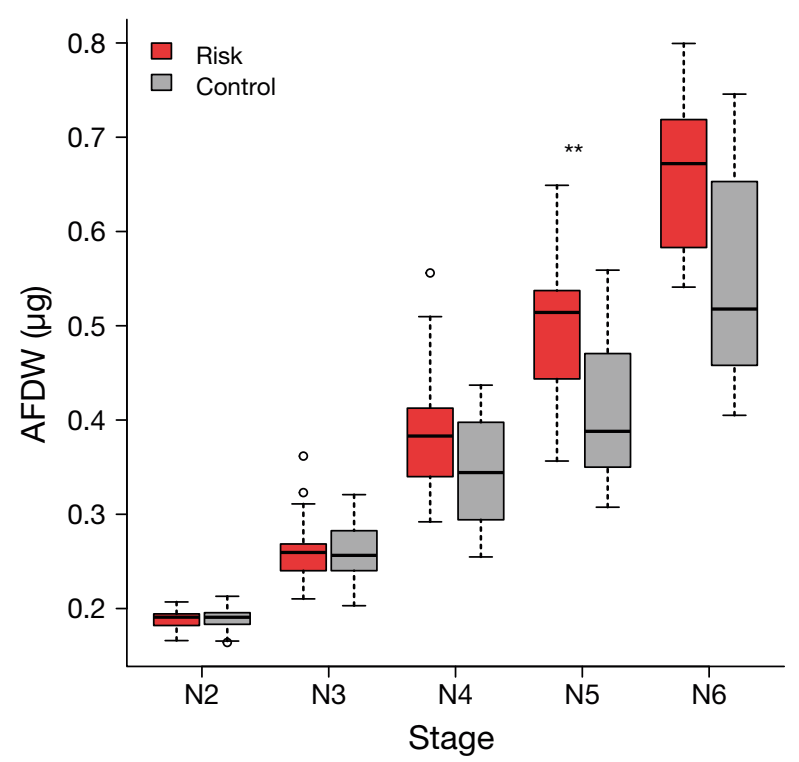

Fig. 3. Body mass, in $\mu g$ ash-free dry weight (AFDW), in Temora longicornis naupliar stages N2 to N6 with risk and control treatment. Horizontal lines are medians, the boxes represent 25 th and 75 th percentiles, and the dashed vertical lines extend to the extreme values or to 1.5 times interquartile range. No individuals from the control group reached stage $\mathrm{C} 1 .^{* *}$ indicates a significantly higher AFDW in the risk treatment (Wilcoxon rank sum test, $\mathrm{n}=20, \mathrm{~m}=17$,

$$
\mathrm{p}=0.0058 \text { ) }
$$

$\mathrm{n}=20, \mathrm{~m}=20, \mathrm{p}=0.081 ; \mathrm{N} 5: \mathrm{n}=20, \mathrm{~m}=17, \mathrm{p}=$ 0.0058 ; $6: \mathrm{n}=9, \mathrm{~m}=6, \mathrm{p}=0.066)$. The aspect ratio was the same for both treatments throughout development ( $p>0.05$ at stages N2 to N6).

The response to risk on molting rate was stage dependent, as indicated by the transition probabilities and the corresponding log odds ratios (Fig. 4a,b). A log odds ratio $<0$ in stages N1 and N5 showed that the molting probability was significantly lower in the risk treatment than in the control treatment in these stages (Fig. 4b). Likewise, a log odds ratio $>0$ in stages N2 and N4 indicated a significantly higher molting rate in the risk treatment. The molting rate was high in both groups at stage N1, which is typical 
when the first stage does not feed (Peterson 2001). Only individuals from the risk treatment reached the first copepodid stage by the end of the experiment. There was considerable individual variation in molting rates. Although all the nauplii survived and were measured throughout the experiment, the number of observations decreased from stage N5 to C1. Over
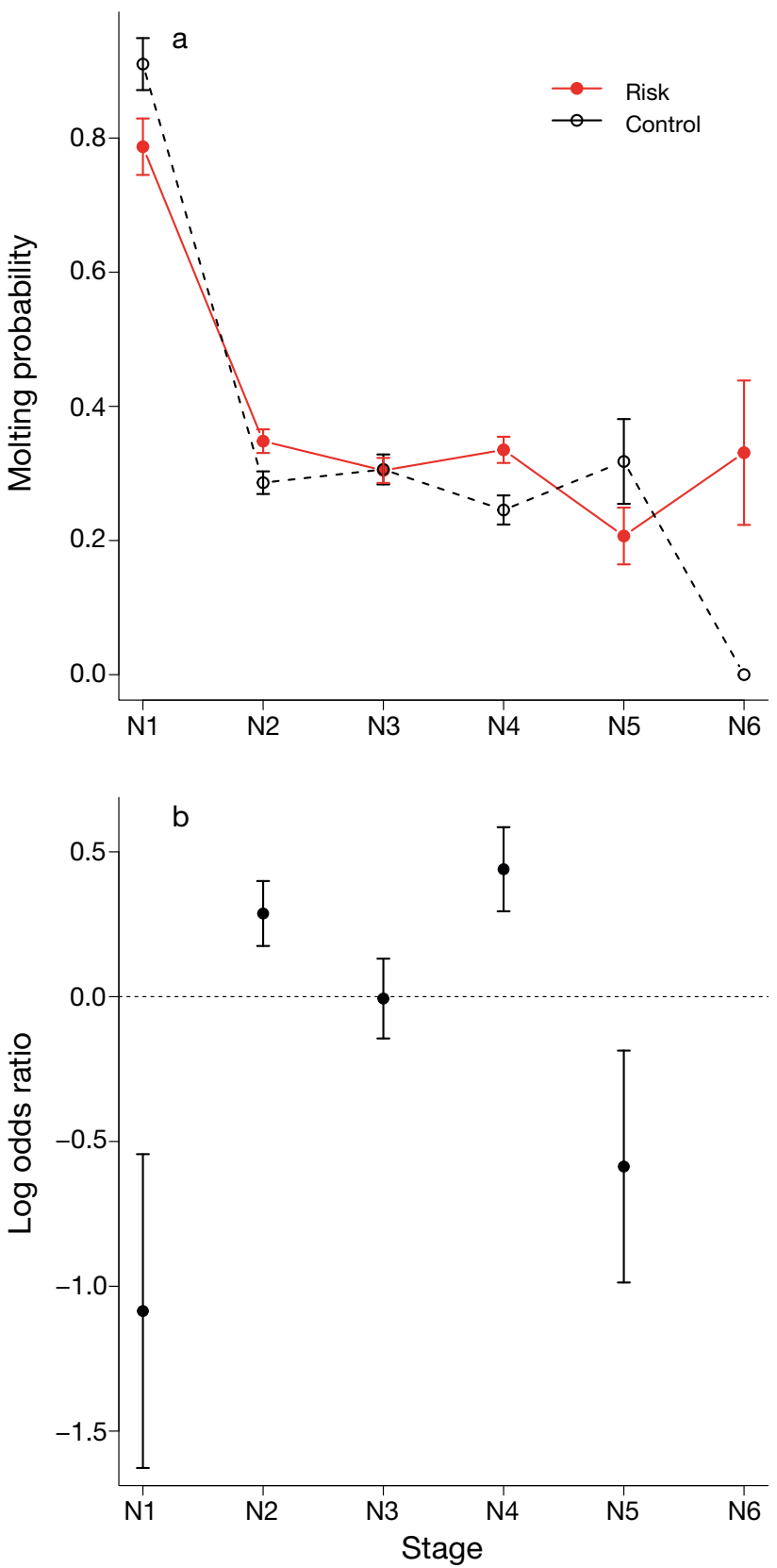

Fig. 4. (a) Molting probabilities for risk and control treatments (mean $\pm \mathrm{SD}$ ), derived from bootstrap sampling of stage observations $(n=1000)$ with replacement. The values are probabilities of molting from the stage indicated on the $x$-axis. (b) Log odds ratio (mean $\pm \mathrm{SD}$ ) for molting probability with risk treatment relative to control (Eq. 8) for each stage time, risk generated a higher proportion of N5 and $\mathrm{C} 1$, and a lower proportion of N4 and N6, according to our matrix projections for a simulated cohort (Fig. 5a,b). When accounting for the treatment effect on stage-specific AFDW, an increase in the mean individual AFDW for a cohort with elevated risk became clear (Fig. 5c).

\section{DISCUSSION}

In stage-structured development, a higher growth rate can be achieved by increasing the size increment per stage, accelerating the molting rate, or both. Here, a combination of stage-dependent increase of molting rate and AFDW resulted in a higher overall growth rate in the nauplii when exposed to the chemical risk cue. The effect was most pronounced during the late naupliar stages (N4 to N6).

The increased growth rate with risk indicates that the advantages of large size outweigh the costs of higher predator-encounter rates. Behavioral defenses, which are fundamental to copepod survival, develop with size. Generally, propulsion becomes more efficient as the Reynolds number increases (Andersen Borg et al. 2012), and escape jump velocity increases with larger size (Kiørboe \& Visser 1999, Bradley et al. 2013). Moreover, larger individuals within a species may adjust their vertical distribution to account for the perceived risk (De Robertis 2002, Titelman \& Fiksen 2004). These advantages of larger size could explain why our results contradict several studies on cladocerans showing allocation of resources to early reproduction (Machá ek 1991, Stibor 1992, Reede 1995). While copepods are specialized in sophisticated escape responses, cladocerans are less motile and rely more on high reproductive rates and morphological defenses. A limnetic calanoid copepod also responded to fish kairomones by investing less in growth (Gutierrez et al. 2010), perhaps suggesting that investment in growth is more costly or less rewarding in fresh water than in the sea. A freshwater snail, however, invests more in growth with predator cues (Crowl \& Covich 1990). The juvenile snails were under high predation pressure before they eventually grew into a size refuge. Copepods do not outgrow the prey size range of fish predators, yet they apparently have some advantages of size that might compensate for higher vulnerability. For instance, copepods also benefit reproductively by investment in growth with larger individuals having higher egg production and mating rates (Sichlau \& Kiørboe 2011). 

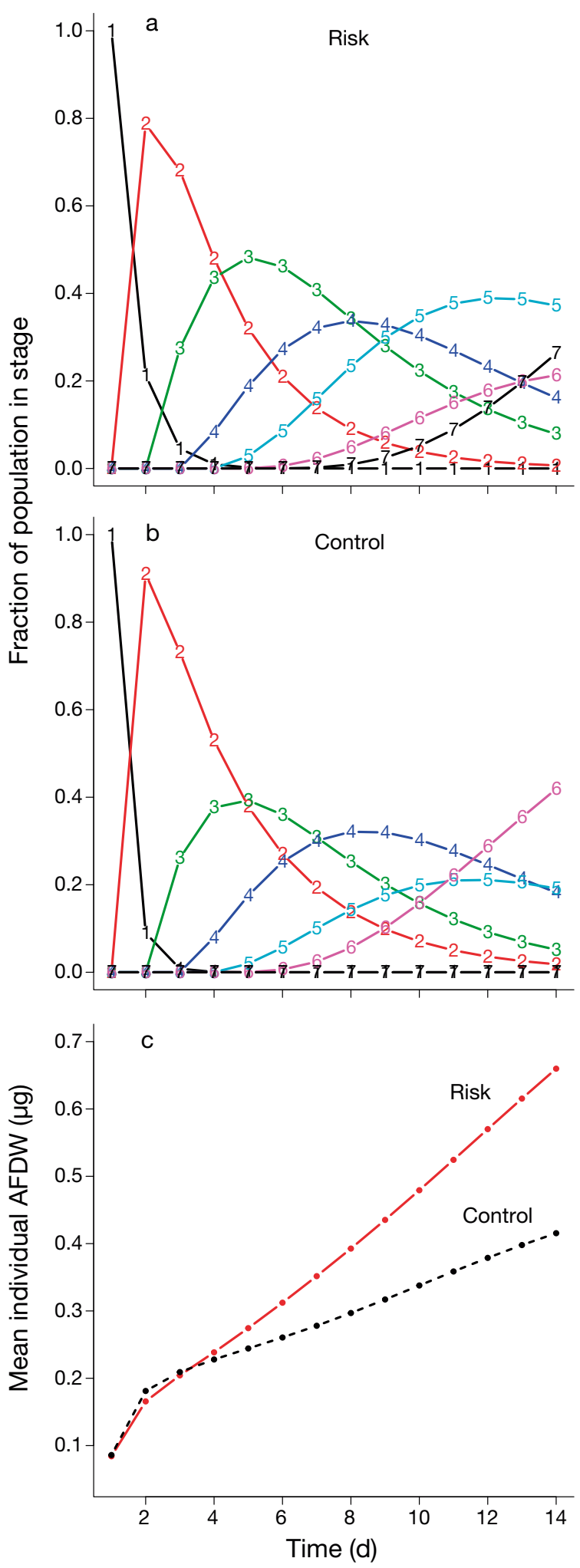

Fig. 5. (a,b) Simulated stage frequency distribution over $14 \mathrm{~d}$ for a cohort with (a) risk and (b) control treatment. Stage frequencies are estimated by projection of transition probability matrices for each treatment on the initial stage frequency (Eq. 10). (c) Estimated individual ash-free dry weight (AFDW) in population cohorts with and without risk
Stage-specific responses may reflect different optimal strategies based on ontogenetic changes in vulnerability and defense. The decreased molting probability found in the earliest nauplii with risk treatment might be induced to extend the stage with the lowest risk of encountering fish. Nauplii in stage N1 are small, inactive and do not feed, and therefore these nauplii are the least exposed to visual predators. Up to stage N3, they only have 3 appendages, which makes their motility weak and energetically inefficient (Titelman \& Kiørboe 2003, Andersen Borg et al. 2012). At stages N4 to N6, rudimentary appendages appear, and swimming behavior changes to a more continuous mode (Titelman \& Kiørboe 2003) with a strong hovering feeding current (Bruno et al. 2012), making them more conspicuous. Interestingly, the risk treatment tended to induce a higher molting rate in the late naupliar stages, and only individuals with risk treatment reached $\mathrm{C} 1$ during the experiment (Figs. $3 \& 4$ ). Speeding up development could be a means of reaching $\mathrm{C} 1$ earlier. The transition from nauplius to copepodite involves large morphological changes that make copepodites far more likely to escape predators successfully than nauplii (Andersen Borg et al. 2012, Bradley et al. 2013). As pointed out by Kiørboe \& Sabatini (1995), vulnerability must have selected for the generally shorter stage durations in nauplii compared with copepodites.

Ontogenetic differences in responses to risk might also arise from development of the sensory apparatus. The exact point at which nauplii acquire chemosensitivity is unfortunately not known. However, chemical information is assumingly perceived by sensillae on the antennules (Gill 1986), and potentially also on the integument and the cephalic appendages (reviewed in Heuschele \& Selander 2014). Early nauplii (N1 to N3) have short antennules with few sensillae. From N4 onwards, the antennules become progressively more segmented and the number of sensillae increases (Mauchline 1998, Bruno et al. 2012). Thus, late nauplii are probably more sensitive to the predator cue than early nauplii.

Although copepods develop chemosensitivity, we cannot be sure that they detect and respond to fish kairomones in the field. Our results show a potential for response to fish kairomones under experimental conditions. But even though an average density of 2 sticklebacks $l^{-1}$ is unrealistic in nature, high densities of planktivorous fish might occur when they form dense schools (Keenleyside 1955). There is also spatial correlation between copepods and high fish densities. Copepods are naturally aggregated by environmental forcing, such as tidal currents and density 
gradients, or by swarming. These copepod patches in turn attract fish predators (Alldredge \& Hamner 1980, Bertrand et al. 2008), implying that copepods are sometimes exposed to high concentrations of predator cues. In addition, the stickleback kairomone is probably far more persistent in natural systems than in small-scale incubations. The reason for this is degradation of the cue by surface-associated bacteria and adsorption of the cue to surfaces in small vessels (Loose et al. 1993, von Elert \& Pohnert 2000).

Also, the complexity of chemical information in the sea is much greater than in our experimental set-up. Copepods might be under the influence of a variety of cues from functionally different predators, perhaps modifying the detection and response to fish kairomones. For the smallest nauplii, the risk of fish predation is most likely low compared with that of invertebrate predators (Titelman \& Fiksen 2004) and fish predation becomes relatively more important as they outgrow some of their planktonic predators (Fiksen et al. 2005, Tönnesson \& Tiselius 2005). Nevertheless, fish kairomones are found to induce effects on behavior in marine copepods, such as reduced swimming behavior (van Duren \& Videler 1996) and a changed diel vertical migration pattern (Cohen \& Forward 2005). These observations support the hypothesis than marine copepods have evolved the ability to recognize fish predators by chemical cues.

Incubation of fish inevitably increases the level of nitrogen and bacteria in the water, which could potentially enhance growth conditions (Maszczyk \& Bartosiewicz 2012). However, even for small copepod nauplii, bacteria are well below the optimal prey size range (Berggreen et al. 1988). As the nauplii were fed excess amounts of a nutritionally complete phytoplankton in the optimal size range (Berggreen et al. 1988, Koski 2006), nutritional effects of bacteria were most likely negligible. Also, the nitrogen supply by Rhodomonas sp. $\left(\sim 120 \mu \mathrm{g} \mathrm{l}^{-1}\right)$ was clearly sufficient to avoid growth limitation of the nauplii (Koski 2006). The flip side of high food availability in the experiment might be an unrealistic growth response. Normally, there are high risk costs associated with feeding, which is why feeding is expected to decrease under elevated predation risk (Lima \& Dill 1990, Tiselius et al. 1997).

In conclusion, this study revealed a potential in marine copepod nauplii for adjusting their growth and development patterns in response to fish kairomones. Our results suggest a general increase in size in cohorts of nauplii that experience increased risk during development (Fig. 5c). Body size is a key factor in food web structure (Woodward et al. 2005) and the prey size range of marine predators are typically restricted by detection or gape limitations (Verity \& Smetacek 1996). Given that corresponding effects exist in the field, predators have a more important role than previously assumed in shaping life history traits in marine copepods with potential implications for the plankton community at large.

Acknowledgements. This study was financed by the University of Oslo. We thank H. E. Karlsen for assistance at the Marine Research Station in Drøbak during the experiment and S. Brubak for help with algal cultures. We also thank the 3 reviewers for their constructive comments.

\section{LITERATURE CITED}

Abrams PA, Leimar O, Nylin S, Wiklund C (1996) The effect of flexible growth rates on optimal sizes and development times in a seasonal environment. Am Nat 147: 381-395

Aksnes DL, Utne ACW (1997) A revised model of visual range in fish. Sarsia 82:137-147

Alldredge AL, Hamner WM (1980) Recurring aggregation of zooplankton by a tidal current. Estuar Coast Mar Sci 10: 31-37

Andersen Borg CM, Bruno E, Kiørboe T (2012) The kinematics of swimming and relocation jumps in copepod nauplii. PLoS ONE 7:e47486

Berggreen U, Hansen B, Kiørboe T (1988) Food size spectra, ingestion and growth of the copepod Acartia tonsa during development: implications for determination of copepod production. Mar Biol 99:341-352

Bergkvist J, Thor P, Jakobsen HH, Wängberg SA, Selander E (2012) Grazer-induced chain length plasticity reduces grazing risk in a marine diatom. Limnol Oceanogr 57: 318-324

Bertrand A, Gerlotto F, Bertrand S, Gutiérrez M and others (2008) Schooling behaviour and environmental forcing in relation to anchoveta distribution: an analysis across multiple spatial scales. Prog Oceanogr 79:264-277

Bradley CJ, Strickler JR, Buskey EJ, Lenz PH (2013) Swimming and escape behavior in two species of calanoid copepods from nauplius to adult. J Plankton Res 35: 49-65

> Breteler WCMK, Fransz HG, Gonzalez SR (1982) Growth and development of four calanoid copepod species under experimental and natural conditions. Neth J Sea Res 16: 195-207

Breteler WCMK, Schogt N, Gonzalez SR (1990) On the role of food quality in grazing and development of life stages, and genetic change of body size during cultivation of pelagic copepods. J Exp Mar Biol Ecol 135:177-189

$>$ Bruno E, Andersen Borg CM, Kiørboe T (2012) Prey detection and prey capture in copepod nauplii. PLoS ONE 7: e47906

Buskey EJ, Lenz PH, Hartline DK (2002) Escape behavior of planktonic copepods in response to hydrodynamic disturbances: high speed video analysis. Mar Ecol Prog Ser 235:135-146

Caswell H (1989) Matrix population models. Sinauer Associates, Sunderland, MA

> Chase JM (1999) Food web effects of prey size refugia: vari- 
able interactions and alternative stable equilibria. Am Nat 154:559-570

> Cohen JH, Forward RB (2005) Photobehavior as an inducible defense in the marine copepod Calanopia americana. Limnol Oceanogr 50:1269-1277

Cook K, Bunker A, Hay S (2007) Naupliar development times and survival of the copepods Calanus helgolandicus and Calanus finmarchicus in relation to food and temperature. J Plankton Res 29:757-767

$>$ Crowl TA, Covich AP (1990) Predator-induced life-history shifts in a freshwater snail. Science 247:949-951

> De Robertis A (2002) Size-dependent visual predation risk and the timing of vertical migration: an optimization model. Limnol Oceanogr 47:925-933

> Ferrari MCO, Wisenden BD, Chivers DP (2010) Chemical ecology of predator-prey interactions in aquatic ecosystems: a review and prospectus. Can J Zool 88:698-724

- Fields DM, Yen J (1997) The escape behavior of marine copepods in response to a quantifiable fluid mechanical disturbance. J Plankton Res 19:1289-1304

Fiksen Ø, Eliassen S, Titelman J (2005) Multiple predators in the pelagic: modelling behavioural cascades. J Anim Ecol 74:423-429

Forster J, Hirst AG, Woodward G (2011) Growth and development rates have different thermal responses. Am Nat 178:668-678

- Gill CW (1986) Suspected mechano- and chemosensory structures of Temora longicornis (Copepoda: Calanoida). Mar Biol 93:449-457

Gutierrez MF, Paggi JC, Gagneten AM (2010) Fish kairomones alter life cycle and growth of a calanoid copepod. J Plankton Res 32:47-55

> Gutierrez MF, Gagneten AM, Paggi JC (2011) Behavioural responses of two cladocerans and two copepods exposed to fish kairomones. Mar Freshwat Behav Physiol 44: 289-303

> Hay ME, Kubanek J (2002) Community and ecosystem level consequences of chemical cues in the plankton. J Chem Ecol 28:2001-2016

Hessen DO, van Donk E (1993) Morphological changes in scenedesmus induced by substances released from Daphnia. Arch Hydrobiol 127:129-140

> Heuschele J, Selander E (2014) The chemical ecology of copepods. J Plankton Res, 36:895-913

Huntley ME, Lopez MDG (1992) Temperature-dependent production of marine copepods: a global synthesis. Am Nat 140:201-242

Kammenga J, Gestel C, Van EH (2001) Switching lifehistory sensitivities to stress in soil invertebrates. Ecol Appl 11:226-238

Keenleyside MHA (1955) Some aspects of the schooling behaviour of fish. Behaviour 8:183-248

> Kiørboe T, Sabatini M (1995) Scaling of fecundity, growth and development in marine planktonic copepods. Mar Ecol Prog Ser 120:285-298

Kiørboe T, Visser A (1999) Predator and prey perception in copepods due to hydromechanical signals. Mar Ecol Prog Ser 179:81-95

Koski M (2006) Life-stage-specific differences in exploitation of food mixtures: diet mixing enhances copepod egg production but not juvenile development. J Plankton Res 28:919-936

Koski M, Breteler WK, Schogt N (1998) Effect of food quality on rate of growth and development of the pelagic copepod Pseudocalanus elnogatus (Copepoda, Calanoida).
Mar Ecol Prog Ser 170:169-187

> Lasley-Rasher RS, Yen J (2012) Predation risk suppresses mating success and offspring production in the coastal marine copepod, Eurytemora herdmani. Limnol Oceanogr 57:433-440

Lass S, Spaak P (2003) Chemically induced anti-predator defences in plankton: a review. Hydrobiologia 491: 221-239

> Lima SL, Dill LM (1990) Behavioral decisions made under the risk of predation: a review and prospectus. Can J Zool 68:619-640

> Long JD, Smalley GW, Barsby T, Anderson JT, Hay ME (2007) Chemical cues induce consumer-specific defenses in a bloom-forming marine phytoplankton. Proc Natl Acad Sci USA 104:10512-10517

Loose CJ, Vonelert E, Dawidowicz P (1993) Chemicallyinduced diel vertical migration in Daphnia: a new bioassay for kairomones exuded by fish. Arch Hydrobiol 126:329-337

Macháček J (1991) Indirect effect of planktivorous fish on the growth and reproduction of Daphnia galeata. Hydrobiologia 225:193-197

Macháček J (1995) Inducibility of life history changes by fish kairomone in various developmental stages of Daphnia. J Plankton Res 17:1513-1520

Maszczyk P, Bartosiewicz M (2012) Threat or treat: the role of fish exudates in the growth and life history of Daphnia. Ecosphere 3:art91

Mauchline J (1998) The biology of calanoid copepods. In: Blaxter JHS, Southward AJ, Tyler PA (eds) Advances in marine biology, Book 33. Academic Press, San Diego, CA

> Neill WE (1992) Population variation in the ontogeny of predator-induced vertical migration of copepods. Nature Zooplankton sheet 356:54-57

> Nylin S, Gotthard K (1998) Plasticity in life-history traits. Annu Rev Entomol 43:63-83

Ogilvie HS (1953) Copepod nauplii (I). Cons Int Explor Mer Zooplankton sheet 50:1-4

Peterson WT (2001) Patterns in stage duration and development among marine and freshwater calanoid and cyclopoid copepods : a review of rules, physiological constraints, and evolutionary significance. Hydrobiologia 453/454:91-105

Pinheiro J, Bates D, DebRoy S, Deepayan S, R Core Team (2013) nlme: linear and nonlinear mixed effects models. $\mathrm{R}$ package version 3.1-117. http://CRAN.R-project.org/ package $=$ nlme

Rasband WS (2011) ImageJ. US National Institutes of Health, Bethesda, MD. http://imagej.nih.gov/ij/

R Core Team (2010) R: a language and environment for statistical computing. R Foundation for Statistical Computing, Vienna

Reede T (1995) Life history shifts in response to different levels of fish kairomones in Daphnia. J Plankton Res 17 : 1661-1667

Selander E, Jakobsen HH, Lombard F, Kiørboe T (2011) Grazer cues induce stealth behavior in marine dinoflagellates. Proc Natl Acad Sci USA 108:4030-4034

Sichlau M, Kiørboe T (2011) Age- and size-dependent mating performance and fertility in a pelagic copepod, Temora longicornis. Mar Ecol Prog Ser 442:123-132

Stearns SC (1992) The evolution of life histories. Oxford University Press, New York, NY

Stibor H (1992) Predator induced life-history shifts in a freshwater cladoceran. Oecologia 92:162-165 
Tiselius P, Jonsson PR, Kaartvedt S, Olsen ME, Jarstad T (1997) Effects of copepod foraging behavior on predation risk: an experimental study of the predatory copepod Pareuchaeta norvegica feeding on Acartia clausi and A. tonsa (Copepoda). Limnol Oceanogr 42:164-170

Titelman J (2001) Swimming and escape behavior of copepod nauplii: implications for predator-prey interactions among copepods. Mar Ecol Prog Ser 213:203-213

Titelman J, Fiksen O (2004) Ontogenetic vertical distribution patterns in small copepods: field observations and model predictions. Mar Ecol Prog Ser 284:49-63

Titelman J, Kiørboe T (2003) Motility of copepod nauplii and implications for food encounter. Mar Ecol Prog Ser 247: 123-135

Tönnesson K, Tiselius P (2005) Diet of the chaetognaths Sagitta setosa and $S$. elegans in relation to prey abundance and vertical distribution. Mar Ecol Prog Ser 289: $177-190$

Turner J (2004) The importance of small planktonic copepods and their roles in pelagic marine food webs. Zool Stud 43:255-266

Urban MC, Threat GP (2007) The growth-predation risk trade-off under a growing gape-limited predation threat. Ecology 88:2587-2597

Editorial responsibility: Joseph Pawlik, Wilmington, North Carolina, USA van Duren LA, Videler JJ (1996) The trade-off between feeding, mate seeking and predator avoidance in copepods: behavioural responses to chemical cues. J Plankton Res 18:805-818

$>$ Verity PG, Smetacek V (1996) Organism life cycles, predation, and the structure of marine pelagic ecosystems. Mar Ecol Prog Ser 130:277-293

Viitasalo M, Kiørboe T, Flinkman J, Pedersen LW, Visser AW (1998) Predation vulnerability of planktonic copepods: consequences of predator foraging strategies and prey sensory abilities. Mar Ecol Prog Ser 175:129-142

von Elert E, Pohnert G (2000) Predator specificity of kairomones in diel vertical migration of Daphnia: a chemical approach. Oikos 88:119-128

> Wasserman RJ, Froneman PW (2013) Risk effects on copepods: preliminary experimental evidence for the suppression of clutch size by predatory early life-history fish. J Plankton Res 35:421-426

Weissburg MJ, Ferner MC, Pisut DP, Smee DL (2002) Ecological consequences of chemically mediated prey perception. J Chem Ecol 28:1953-1970

> Woodward G, Ebenman B, Emmerson M, Montoya JM, Olesen JM, Valido A, Warren PH (2005) Body size in ecological networks. Trends Ecol Evol 20:402-409

Submitted: March 26, 2014; Accepted: June 12, 2014

Proofs received from author(s): August 19, 2014 